\title{
An Efficient Synthesis of 2-Aminothiophenes via the Gewald Reaction Catalyzed by an $N$-Methylpiperazine-Functionalized Polyacrylonitrile Fiber
}

\author{
Lichao Ma, Liwei Yuan, Changzhu Xu, Guowei Li, Minli Tao, Wenqin Zhang* \\ Department of Chemistry, School of Sciences, Tianjin University, No.92 Weijin Road, Tianjin 300072, P. R. of China \\ Fax+86(22)27403475; E-mail: zhangwenqin@tju.edu.cn \\ Received: 12.09.2012; Accepted after revision: 09.11.2012
}

\begin{abstract}
A new $N$-methylpiperazine-functionalized polyacrylonitrile fiber has been developed to catalyze the Gewald reaction between 2,5-dihydroxy-1,4-dithiane and activated nitriles to afford 3substituted 2-aminothiophenes in good to excellent yields $(65$ $91 \%)$. Low catalyst loading $(8.0 \mathrm{~mol} \%)$, simple procedure, high yields, excellent recyclability, and reusability (up to 10 times with minimal loss of catalytic activity) are attractive features of this fiber catalyst.
\end{abstract}

Key words: Gewald reaction, 2-aminothiophene, $N$-methylpiperazine, polyacrylonitrile fiber, fiber catalyst

2-Aminothiophenes have demonstrated a broad spectrum of uses, including biologically active products, ${ }^{1-4}$ dyes,,${ }^{1 \mathrm{~b}, 5}$ and conducting polymers. ${ }^{1 \mathrm{~b}, 6}$ Traditionally, polysubstituted 2-aminothiophenes with an electron-withdrawing group such as cyano, ethoxycarbonyl, or benzoyl in the 3position and alkyl, aryl, or heteroaryl groups in the 4- and 5-positions are prepared by the Gewald reaction. ${ }^{1}$ To extend the scope of the reaction, many alterations have been made to the original Gewald reaction. ${ }^{1 \mathrm{~b}}$ By varying the reaction components, $\alpha$-sulfanylketone and $\alpha$-sulfanylaldehyde were successfully used to react with an activated nitrile. Furthermore, a wide array of catalysts, including inorganic solid base, ${ }^{7,8}$ acid-base catalyst, ${ }^{9}$ L-proline, ${ }^{10}$ Lewis acid, ${ }^{4}$ and ionic liquids ${ }^{11}$ have been reported to catalyze the Gewald reaction. In addition, microwave $\mathrm{e}^{3,8,12}$ and ultrasonic ${ }^{13}$ irradiation technologies have also been used to promote the Gewald reaction. However, the drawbacks of these methods are high catalyst loading (normally $36-100 \mathrm{~mol} \%$ or even more), long reaction time, nonrecoverable catalyst, multi-step synthesis, and low yield. Accordingly, the development of a simpler and more efficient catalytic method for the synthesis of 3-substituted 2-aminothiophenes under mild conditions remains an attractive field.

Heterogeneous catalyzed organic reactions using immobilized catalysts have been proven to be advantageous over homogeneous ones because of simpler workup, easier recovery of the catalyst, and better reusability. Therefore, heterogeneous catalysts are considered as potential alternatives to homogeneous catalysts in the Gewald reaction.

Polyacrylonitrile fiber (PANF) has excellent mechanical strength and contains an abundance of cyano groups,

SYNTHESIS 2013, 45, 0045-0052

Advanced online publication: 29.11.2012

DOI: 10.1055/s-0032-1316821; Art ID: SS-2012-H0716-OP

(C) Georg Thieme Verlag Stuttgart · New York which can be easily transformed into carboxyl, amide, and other functional groups. ${ }^{14}$ Consequently, PANF is an ideal starting material to prepare various functionalized catalysts.

In this work, we have developed an amine functionalized fiber catalyst to catalyze the Gewald reaction. This aminated fiber catalyst exhibited excellent activity and reusability. To the best of our knowledge, this is the first example of a fiber catalyst used to catalyze the Gewald reaction.

Commercially available PANF was immersed in an aqueous solution of $N$-methyl- $N^{\prime}$-(3-aminopropyl)piperazine and refluxed for eight hours to produce an $N$-methylpiperazine-functionalized fiber catalyst (P-PANF) and the procedure is shown in Scheme 1. As discussed in our previous papers, the amination was strongly influenced by the reaction time and temperature. ${ }^{15}$ The modification extent of P-PANF was measured by weight gain and acid exchange capacity (Table 1). ${ }^{16}$ Moreover, P-PANF was also characterized by IR (Figure 1), SEM (Figure 2), and elemental analyses (EA) (Table 2).

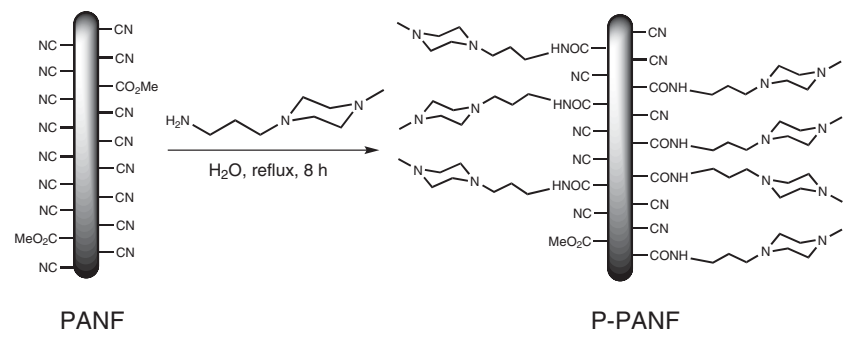

Scheme 1 Preparation of the immobilized fiber catalyst (P-PANF)

Weight gain of the fiber catalyst was calculated as follows: weight gain $=\left[\left(\mathrm{W}_{2}-\mathrm{W}_{1}\right) / \mathrm{W}_{1}\right] \times 100 \%$, where $\mathrm{W}_{1}$ and $\mathrm{W}_{2}$ are the weights of PANF and the aminated fiber, respectively. The weight gain of P-PANF was $23.0 \%$.

Acid exchange capacity of the fiber catalyst in aqueous $0.100 \mathrm{M} \mathrm{HCl}$ was determined to be $2.32 \mathrm{mmol} \mathrm{g}^{-1}$. And this data corresponds to a calculated weight gain of $22.1 \%$ (see Supporting Information), which is in accord with the measured weight gain of $23.0 \%$.

Initial investigations were focused on the catalytic activity of the fiber catalysts, using the model reaction between ethyl cyanoacetate (1a) and 2,5-dihydroxy-1,4-dithiane (2). When the reaction was carried out with $N$-methylpiperazine $(N-\mathrm{MP})$ as the catalyst, a yield of $89 \%$ was ob- 
tained, indicating the high activity of the $\mathrm{N}$ methylpiperazine moiety. Further reactions were carried out in the presence of the fiber catalyst: PANF, $\mathrm{PAN}_{\mathrm{P}} \mathrm{F}-$ $2,{ }^{17} \mathrm{PAN} \mathrm{P}_{\mathrm{P}} \mathrm{F}-3^{17}$ [the functional group for $\mathrm{PAN}_{\mathrm{P}} \mathrm{F}-2$ is $N^{1}$-methyl-3-(methylamino)propylamino and that for $\mathrm{PAN}_{\mathrm{P}} \mathrm{F}-3$ is 3-(dimethylamino)propylamino], or P-PANF. As shown in Table 1, PANF is inactive, $\mathrm{PAN}_{\mathrm{P}} \mathrm{F}-2$ with a secondary amine functional group exhibits a poor activity $\left(11 \%\right.$, yield), while $\mathrm{PAN}_{\mathrm{P}} \mathrm{F}-3$ with a tertiary amine functional group performs a good activity $(86 \%$, yield), and PPANF presents the highest activity $(89 \%$, yield) which equals that of the free $N$-methylpiperazine. These results suggest that the tertiary amine fiber catalysts $\left(\mathrm{PAN}_{\mathrm{P}} \mathrm{F}-3\right.$ and P-PANF) have higher catalytic activity than the secondary amine fiber catalyst $\left(\mathrm{PAN}_{\mathrm{P}} \mathrm{F}-2\right)$ in catalyzing the Gewald reaction. Comparing the two tertiary amine fiber catalysts, P-PANF shows a better activity than $\mathrm{PAN}_{\mathrm{P}} \mathrm{F}-3$, this maybe due to the fact that P-PANF has two tertiary amino groups in each functional unit and the functional chain is longer and more flexible than that of $\mathrm{PAN}_{\mathrm{P}} \mathrm{F}-3$. Therefore, P-PANF was selected as an efficient catalyst for the Gewald reaction.

Table 1 Properties of Different Catalysts and Their Activity in Catalyzing the Gewald Reaction ${ }^{\mathrm{a}}$

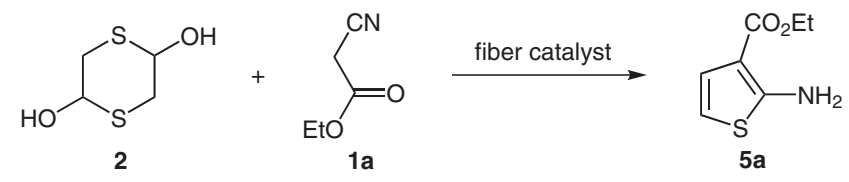

\begin{tabular}{llllll}
\hline Entry & Catalyst & $\begin{array}{l}\text { Weight } \\
\text { gain (\%) }\end{array}$ & $\begin{array}{l}\text { Acid exchange } \\
\text { capacity } \\
\left(\mathrm{mmol} \cdot \mathrm{g}^{-1}\right)\end{array}$ & $\begin{array}{l}\text { Catalyst } \\
\text { loading } \\
(\mathrm{mol} \%)^{\mathrm{b}}\end{array}$ & $\begin{array}{l}\text { Yield } \\
(\%)^{\mathrm{c}}\end{array}$ \\
\hline 1 & Blank & - & - & - & 0 \\
2 & PANF & - & 0 & - & 0 \\
3 & $N-\mathrm{MP}$ & - & - & 10.0 & 89 \\
4 & PANpF-2 & 22.1 & 1.5 & 10.0 & 11 \\
5 & PANpF-3 & 38.0 & 2.8 & 10.0 & 86 \\
6 & P-PANF & 23.0 & 2.32 & 8.0 & 89 \\
\hline
\end{tabular}

${ }^{a}$ Reaction conditions: ethyl cyanoacetate (1a; $\left.5.0 \mathrm{mmol}\right), 2,5$-dihydroxy-1,4-dithiane $(2 ; 2.5 \mathrm{mmol})$, and the fiber catalyst $(8.0 \mathrm{~mol} \%)$ were refluxed in EtOH $(20 \mathrm{~mL})$ for $4 \mathrm{~h}$.

${ }^{\mathrm{b}}$ Catalyst loading: $8.0 \mathrm{~mol} \% \mathrm{P}-\mathrm{PANF}=0.172 \mathrm{~g}$, thus $0.172 \mathrm{~g}$ of

PANF was used in entry 2.

${ }^{\mathrm{c}}$ Isolated yields after column chromatography.

The IR spectra of PANF, P-PANF, P-PANF (recovered $^{\text {(re }}$ after the first use in the Gewald reaction) and $\mathrm{P}-\mathrm{PANF}_{10}$ (recovered after the 10th run of the Gewald reaction) are illustrated in Figure 1. The 2244 and $1731 \mathrm{~cm}^{-1}$ bands in Figure 1a are assigned to the $\mathrm{C} \equiv \mathrm{N}$ and the ester $\mathrm{C}=\mathrm{O}$ stretching vibrations, respectively. After amination, the $\mathrm{C} \equiv \mathrm{N}$ peak and the ester $\mathrm{C}=\mathrm{O}$ peak decrease slightly (Figure $1 \mathrm{~b}$ ), indicating that partial $\mathrm{CN}$ and $\mathrm{CO}_{2} \mathrm{Me}$ groups have participated in the amination. For the IR spectra of P-
PANF, P-PANF 1 , and P-PANF 10 (Figure 1b-d), the broad absorption bands from $3700-3100 \mathrm{~cm}^{-1}$ are attributed to the stretching vibrations of the amide $\mathrm{NH}$. The strong absorption band at $1663 \mathrm{~cm}^{-1}$ and new broad peak at 1583 $\mathrm{cm}^{-1}$ are assigned to the amide I band and the overlap of amide II band, respectively. The IR results suggest that the amine moiety has been grafted on the PANF. Moreover, the IR spectra of P-PANF, P-PANF 1 , and P-PANF 10 (Figure $1 \mathrm{~b}-\mathrm{d}$ ) are almost the same, indicating that most of the functional groups of the fiber catalyst are still there after being used 10 times in the Gewald reaction.

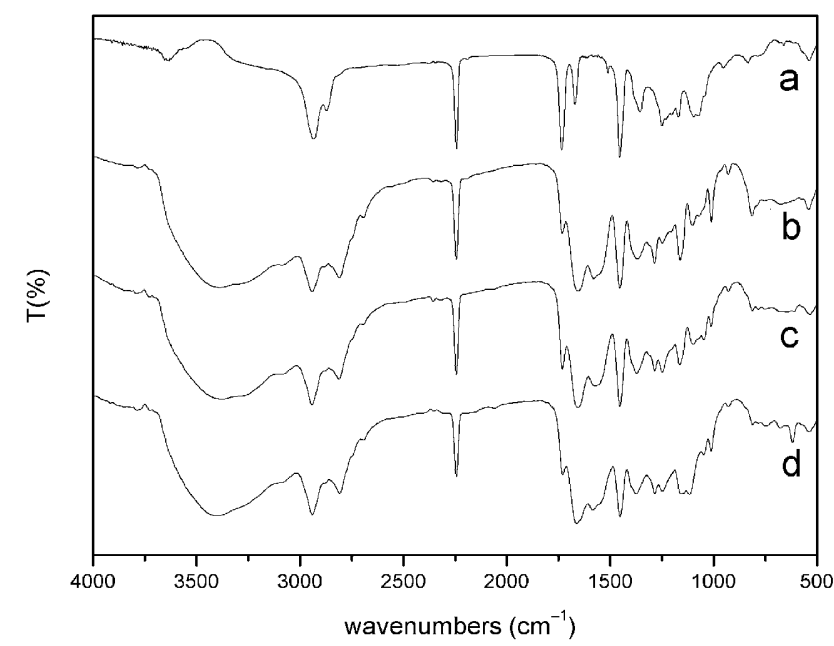

Figure 1 IR spectra of (a) PANF, (b) P-PANF, (c) P-PANF , and (d) P-PANF 10

The SEM photographs of PANF, P-PANF, P-PANF 1 , and P-PANF 10 are illustrated in Figure 2. The surface of the fiber becomes rougher and rougher after the amination and the catalytic reaction (Figure $2 \mathrm{a}-\mathrm{d}$ ). The SEM photograph of P-PANF ${ }_{10}$ (Figure $2 \mathrm{~d}$ ) shows that the surface of the fiber becomes rougher than the newly prepared P-PANF with partial ruptures simultaneously owing to the length of stirring time. However, P-PANF has enough physical strength after being used 10 times in the Gewald reaction.

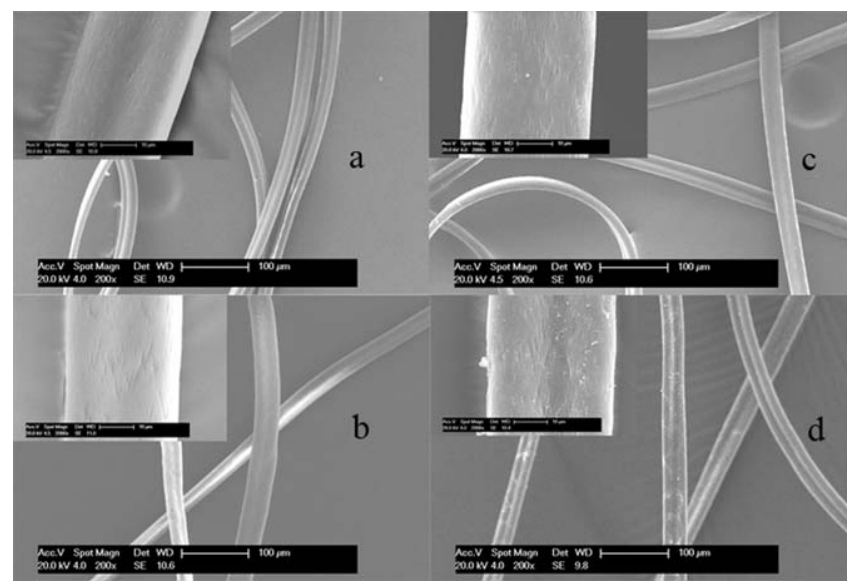

Figure 2 SEM photographs of (a) PANF, (b) P-PANF, (c) P-PANF and (d) P-PANF 10 
The EA data of PANF, P-PANF, P-PANF ${ }_{1}$, and P-PANF 10 are listed in Table 2. Compared to the original PANF, the hydrogen content of P-PANF increases as expected. The increase in the oxygen content going from $\mathrm{CN}$ groups to CONHR groups $[\mathrm{R}=3-(N$-methylpiperazinyl $)$ propyl $]$ leads to the decrease of carbon and nitrogen contents. Because surfactants used in the fabricating process of PANF were removed during the amination process, the content of sulfur is reduced in P-PANF. The carbon, hydrogen, and nitrogen contents of $\mathrm{P}-\mathrm{PANF}_{1}$ decrease slightly, while the sulfur content increases when compared with that of P-PANF. A putative feasibility is that the sulfur containing intermediates are adsorbed on the surface of the fiber catalyst. Compared with the EA data of P-PANF 1 , the carbon, hydrogen, and nitrogen contents of P-PANF 10 decrease apparently, but the sulfur content of P-PANF 10 has a remarkable increase, which is due to the partial hydrolysis of the CONHR group with the release of $N$-methyl- $N^{\prime}$ (3-aminopropyl)piperazine and the continuous absorption of the sulfur containing intermediates or product.

Table 2 Elemental Analyses Data of PANF, P-PANF, P-PANF ${ }_{1}$, and $\mathrm{P}^{-\mathrm{PANF}_{10}}$

\begin{tabular}{llllll}
\hline Entry & Sample & $\mathrm{C}(\%)$ & $\mathrm{H}(\%)$ & $\mathrm{N}(\%)$ & $\mathrm{S}(\%)$ \\
\hline 1 & PANF & 66.06 & 5.81 & 24.42 & 0.25 \\
2 & P-PANF & 61.18 & 7.05 & 22.03 & 0.10 \\
3 & P-PANF $_{1}$ & 60.44 & 6.86 & 20.85 & 1.45 \\
4 & P-PANF $_{10}$ & 56.43 & 6.32 & 18.64 & 4.36 \\
\hline
\end{tabular}

The catalyst dosage was determined next. When 1.6-5.6 mol $\%$ of P-PANF was employed, the yield increased from 70 to $85 \%$ (Table 3 , entries $1-3$ ). When the amount of PPANF was increased to $8.0 \mathrm{~mol} \%$, the reaction proceeded efficiently with an excellent yield of $89 \%$ (Table 3, entry $5)$. When the amount of P-PANF was further increased (up to $12.0 \mathrm{~mol} \%$ ), the yield showed no further increase (Table 3, entries 6 and 7). Therefore, $8.0 \mathrm{~mol} \%$ of PPANF was selected for all subsequent reactions.

After optimization of the catalyst dose, studies were focused on the effect of reaction time. These results are listed in Table 3 (entries 5, 8-12). After four hours, the yield reached its maximum level. However, slight decrease was observed for longer reaction time (Table 3, entries 10-12), this may due to the absorption of the product in the P$\mathrm{PANF}$ and this result was in accord with the increased sulfur content in the EA data of P-PANF 1 (Table 2, entry 3 ). Thus, four hours was chosen as the optimal reaction time for the model reaction.

Gewald reaction is mainly catalyzed by organic or inorganic base, such as diethylamine, triethylamine, morpholine, $\mathrm{NaHCO}_{3}$ and $\mathrm{K}_{2} \mathrm{CO}_{3} \cdot{ }^{1 \mathrm{~b}}$ As shown in Table 1, PANF exhibits no activity for this reaction. When P-PANF was used as the catalyst, the yield is $89 \%$, indicating a high catalytic activity.
Table 3 Optimization of Reaction Conditions ${ }^{\mathrm{a}}$

\begin{tabular}{llll}
\hline Entry & Catalyst loading $(\mathrm{mol} \%)$ & Time $(\mathrm{h})$ & Yield (\%) \\
\hline 1 & 1.6 & 4 & 70 \\
2 & 4.0 & 4 & 80 \\
3 & 5.6 & 4 & 85 \\
4 & 7.2 & 4 & 88 \\
5 & 8.0 & 4 & 89 \\
6 & 9.6 & 4 & 89 \\
7 & 12.0 & 4 & 87 \\
8 & 8.0 & 2 & 82 \\
9 & 8.0 & 3 & 87 \\
10 & 8.0 & 5 & 88 \\
11 & 8.0 & 6 & 87 \\
12 & 8.0 & 7 & 85 \\
\hline
\end{tabular}

${ }^{a}$ Reaction conditions: ethyl cyanoacetate (1a; $\left.5 \mathrm{mmol}\right)$ and 2,5-dihydroxy-1,4-dithiane $(2 ; 2.5 \mathrm{mmol})$ with varying amounts of the fiber catalyst were refluxed in EtOH $(20 \mathrm{~mL})$.

${ }^{\mathrm{b}}$ Isolated yields after column chromatography.

A possible mechanism of the Gewald reaction is shown in Scheme 2. The amino groups in the surface of P-PANF function as Brønsted base to result in the formation of a nucleophilic carbanion 1'. Mercaptoacetaldehyde was then attacked by carbanion $\mathbf{1}^{\prime}$ to generate the intermediate 3. Thereafter, the sulfur anion 4 was generated by loss of a proton. The most crucial step in the Gewald reaction is the final ring-closure process, which is performed as an intramolecular nucleophilic addition of the sulfur anion $\mathbf{4}$ to the triple bond of the cyano group. After the cyclization, target 2-aminothiophenes $\mathbf{5}$ occur exclusively in the amino form and are released from the surface of PPANF. $^{1 b}$

Finally, repeated reactions were carried out to test the recyclability and reusability of the P-PANF using the optimized condition. At the end of each reaction, P-PANF was separated from the reaction system by filtration and washed with ethyl acetate to remove the adsorbed product. Then the recycled P-PANF was dried and used directly in the next cycle. In Table 4, P-PANF exhibits excellent recyclability and reusability (up to 10 times) with slightly decrease in activity.

Based on the above results, a series of activated nitriles containing different substituents (see Supporting Information) were selected to react with 2,5-dihydroxy-1,4-dithiane (2) using the optimized conditions. As listed in Table 5 , it can be seen that the reactions proceeded smoothly to give the corresponding 2-aminothiophenes in good to excellent yields, indicating that the P-PANF presents high catalytic activity for the Gewald reaction. Ethyl cyanoacetate (1a), malononitrile (1b), and cyanoacetamides 1c and 1d exhibited high yields above $87 \%$ for their high ac- 


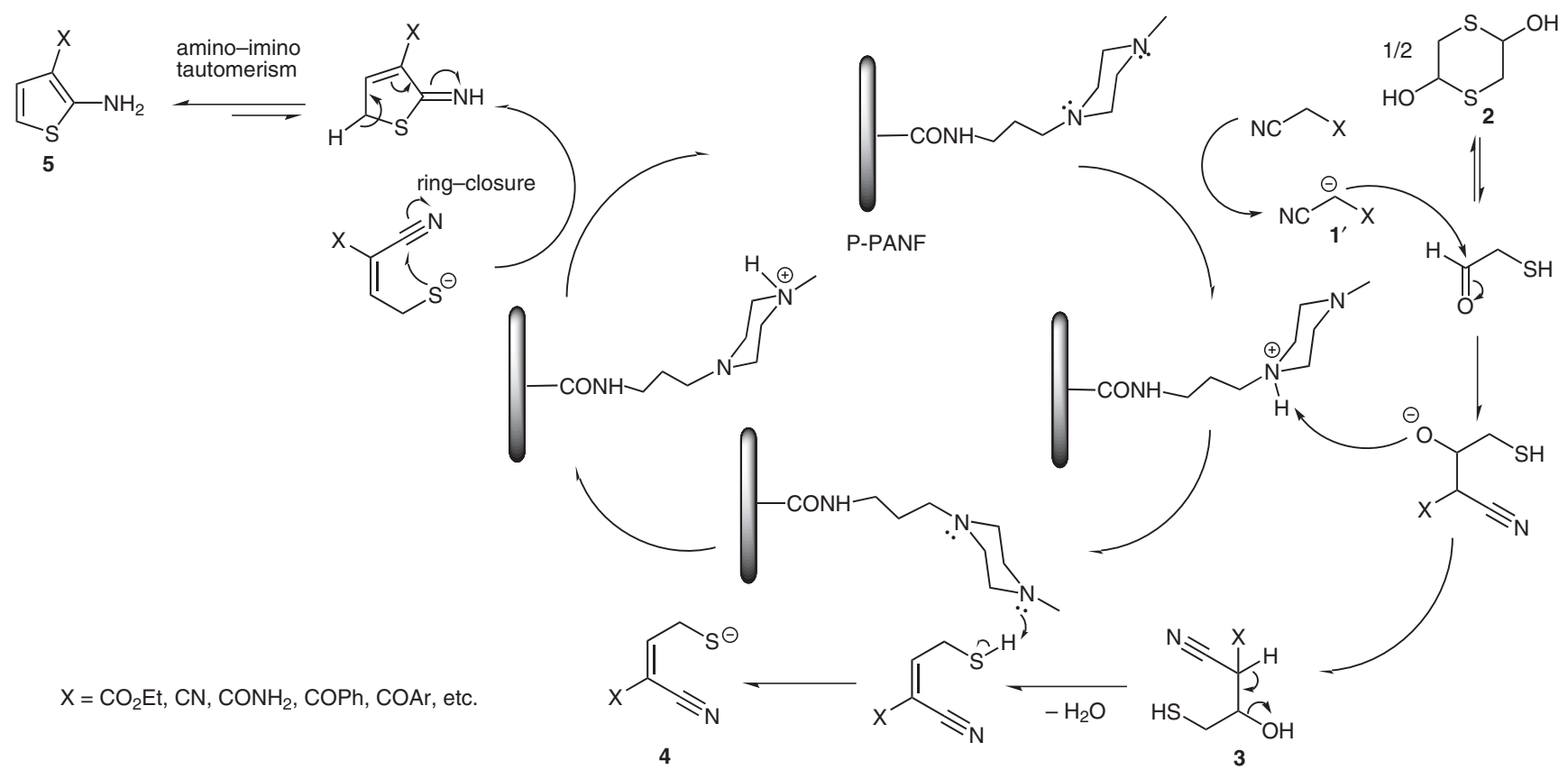

Scheme 2 Possible mechanism of the Gewald reaction catalyzed by P-PANF

Table 4 Recyclability and Reusability of P-PANFa

\begin{tabular}{ll}
\hline Recycling run & Yield $(\%)^{\mathrm{b}}$ \\
\hline 1 & 89 \\
2 & 89 \\
3 & 88 \\
4 & 87 \\
5 & 86 \\
6 & 87 \\
7 & 86 \\
8 & 86 \\
9 & 86 \\
10 & 85 \\
\hline
\end{tabular}

${ }^{a}$ Reaction conditions: ethyl cyanoacetate (1a; $\left.5.0 \mathrm{mmol}\right), 2,5$-dihydroxy-1,4-dithiane $(2 ; 2.5 \mathrm{mmol})$, and the fiber catalyst $(8.0 \mathrm{~mol} \%)$ were refluxed in EtOH $(20 \mathrm{~mL})$ for $4 \mathrm{~h}$.

${ }^{\mathrm{b}}$ Isolated yields after column chromatography.

tivity and less steric effect (Table 5, entries 1-4). When benzoylacetonitriles were used, a little decrease in the yields was observed due to the electron-donating effect of the phenyl group. Substrates possessing electron-withdrawing group such as $\mathrm{Cl}$ at the benzene ring (entry 9) gave the highest yield in all cases of benzoylacetonitrile derivatives (entries 5-9) as expected. Moreover, steric effect on the benzene ring was also considered. The $o$-methylbenzoylacetonitrile (1f) and its para-isomer $\mathbf{1 g}$ gave almost the same yields (entries 6 and 7), suggesting that the main effect is electronic in nature rather than steric at the benzene ring.

Compared to the other catalysts reported in the literature, our catalyst system has some prominent advantages such as lower catalyst loading, shorter reaction time and higher yields. For example, the reaction between 2-cyano- $N$ phenylacetamide (1d) and 2,5-dihydroxy-1,4-dithiane (2) with $36 \mathrm{~mol} \%$ of triethylamine catalyst under microwave irradiation gave a yield of $87 \%{ }^{3}$ However, our catalyst system provided a higher yield of $89 \%$ with only 8.0 $\mathrm{mol} \%$ of the fiber catalyst (Table 5 , entry 4 ). Compared to DBU $\left(60 \mathrm{~mol} \%\right.$ at $60{ }^{\circ} \mathrm{C}$ for $8 \mathrm{~h}$, yield $\left.57 \%\right),{ }^{6}$ our fiber catalyst was more efficient for the same reaction between malononitrile (1b) and 2,5-dihydroxy-1,4-dithiane (2) $\left(8.0 \mathrm{~mol} \%\right.$ of the fiber catalyst at $80^{\circ} \mathrm{C}$ for $2 \mathrm{~h}$, yield $\left.91 \%\right)$ (Table 5, entry 2). The reaction between 2-cyanoacetamide (1c) and 2,5-dihydroxy-1,4-dithiane (2) with triethylamine $(100 \mathrm{mmol} \%)$ conducted at $50{ }^{\circ} \mathrm{C}$ for 4 hours gave only a yield of $72 \%$, ${ }^{2 \mathrm{~d}}$ whereas under our catalyst system, the reaction yield was $87 \%$ using only $8.0 \mathrm{~mol} \%$ of the fiber catalyst (Table 5 , entry 3 ). So we can conclude that our fiber catalyst (P-PANF) can facilely and efficiently catalyze the Gewald reaction. 
Table 5 Reaction of Activated Nitriles with 2,5-Dihydroxy-1,4-dithiane

\begin{tabular}{|c|c|c|c|c|}
\hline Entry & Activated nitrile & 2-Aminothiophene & Time (h) & Yield $(\%)^{b}$ \\
\hline 1 & $1 \mathrm{a}$ & $5 a$ & 4 & 89 \\
\hline 2 & $1 \mathrm{~b}$ & $5 \mathbf{b}$ & 2 & 91 \\
\hline 3 & $1 \mathrm{c}$ & $5 c$ & 4 & 87 \\
\hline 4 & 1d & $5 d$ & 4 & 89 \\
\hline 5 & $1 e$ & $5 e$ & 5 & 83 \\
\hline 6 & 1f & $5 f$ & 6 & 81 \\
\hline 7 & $1 \mathrm{~g}$ & $5 g$ & 6 & 82 \\
\hline 8 & $1 \mathrm{~h}$ & $5 \mathrm{~h}$ & 7 & 80 \\
\hline 9 & 11 & 51 & 5 & 85 \\
\hline 10 & $\mathbf{1 j}$ & $5 j$ & 5 & 83 \\
\hline 11 & $1 \mathrm{k}$ & $5 \mathbf{k}$ & 4 & 83 \\
\hline 12 & 11 & 51 & 4 & 82 \\
\hline
\end{tabular}


Table 5 Reaction of Activated Nitriles with 2,5-Dihydroxy-1,4-dithiane ${ }^{\text {a }}$ (continued)

Entry Activated nitrile

${ }^{a}$ Reaction conditions: activated nitrile $\mathbf{1}(5.0 \mathrm{mmol}), 2,5$-dihydroxy-1,4-dithiane $(2 ; 2.5 \mathrm{mmol})$, and the fiber catalyst $(8.0 \mathrm{~mol} \%)$ were refluxed in $\mathrm{EtOH}(20 \mathrm{~mL})$ for the given time.

${ }^{\mathrm{b}}$ All the yields were isolated yield after column chromatography except $\mathbf{5 n}$, which was purified by column chromatography and recrystallization from $\mathrm{EtOH}$.

In summary, a new fiber catalyst (P-PANF) for Gewald reaction was prepared directly from polyacrylonitrile fiber and $N$-methyl- $N^{\prime}$-(3-aminopropyl)piperazine in a one-step reaction. This fiber catalyst can be utilized to catalyze numerous activated nitriles to react with 2,5-dihydroxy-1,4dithiane (2) under reflux in ethanol and the 3-substituted 2-aminothiophenes were obtained in good to excellent yields $(65-91 \%)$. At the end of the reaction, the fiber catalyst can be easily separated from the reaction system by simple filtration and dryness, and used directly in the next cycle. Moreover, this fiber catalyst also shows excellent recyclability and reusability (at least 10 times) with minimal loss of catalytic activity. To the best of our knowledge, this is the first example of a fiber catalyst that was used to catalyze the Gewald reaction. Low catalyst loading, simple procedure, high yields, excellent recyclability and reusability are attractive features of this fiber catalyst, which provide a novel and powerful tool for the synthesis of 3-substituted 2-aminothiophenes through the Gewald reaction.

IR spectra were obtained with an Avatar360 FTIR spectrometer (Thermo Nicolet). Elemental analyses were performed on an Elementar vario EL analyzer. Philips XL-30 scanning electron microscope (SEM) was used to characterize the surface of the modified fibers. Column chromatography was performed on silica gel 200-300 mesh. ${ }^{1} \mathrm{H}$ NMR (400 MHz) and ${ }^{13} \mathrm{C}$ NMR (101 MHz) spectra were recorded on a Bruker Avance III spectrometer in $\mathrm{CDCl}_{3}$, DMSO- $d_{6}$, or $\mathrm{D}_{2} \mathrm{O}$ using TMS as the internal standard. HRMS were recorded on a Varian 7.0 T FTMS spectrometer. Melting points were taken on a Yanagimoto MP-500 apparatus and are uncorrected. Petroleum ether (PE) used was the fraction boiling in the 60-90 ${ }^{\circ} \mathrm{C}$ range.

\section{$N$-Methyl- $N^{\prime}$-(3-aminopropyl)piperazine}

3-(4-Methylpiperazinyl)propanenitrile: Acrylonitrile (58.4 g, 1.1 mol) was added dropwise to a solution of $N$-methylpiperazine $(100.2 \mathrm{~g}, 1.0 \mathrm{~mol})$ in $\mathrm{EtOH}(180 \mathrm{~mL})$ and the mixture was stirred at r.t. for $3 \mathrm{~h}$. The solvent was evaporated and the residue was distilled at $117-119^{\circ} \mathrm{C} / 4 \mathrm{mmHg}$ to give 3-(4-methylpiperazinyl)propanenitrile as a yellow oil; yield: $150.0 \mathrm{~g}(89 \%)$.

${ }^{1} \mathrm{H} \mathrm{NMR}\left(400 \mathrm{MHz}, \mathrm{CDCl}_{3}\right): \delta=2.70(\mathrm{t}, J=7.0 \mathrm{~Hz}, 2 \mathrm{H}), 2.59-2.40$ $(\mathrm{m}, 10 \mathrm{H}), 2.29(\mathrm{~s}, 3 \mathrm{H}) .^{18}$
$N$-Methyl-N'-(3-aminopropyl)piperazine: A solution of 3-(4-methylpiperazinyl)propanenitrile $(46.0 \mathrm{~g}, 0.3 \mathrm{~mol})$ in anhyd EtOH (360 $\mathrm{mL})$ was treated with small portions of sodium $(32.2 \mathrm{~g}, 1.4 \mathrm{~mol})$. The reaction mixture was refluxed with stirring until the total consumption of 3-(4-methylpiperazinyl)propanenitrile and sodium. After cooling to $50{ }^{\circ} \mathrm{C}, \mathrm{H}_{2} \mathrm{O}(150 \mathrm{~mL})$ was added (Caution! traces of $\mathrm{Na})$. The product was then extracted with $\mathrm{CH}_{2} \mathrm{Cl}_{2}(3 \times 100 \mathrm{~mL})$. The combined organic extracts were washed with brine $(150 \mathrm{~mL})$ and dried $\left(\mathrm{Na}_{2} \mathrm{SO}_{4}\right)$. Evaporation of the solvent and distillation of the residue at $94-96{ }^{\circ} \mathrm{C} / 5 \mathrm{mmHg}$ gave $N$-methyl- $N$ '-(3-aminopropyl)piperazine as a colorless oil; yield: $18.9 \mathrm{~g}(40 \%)$.

${ }^{1} \mathrm{H}$ NMR $\left(400 \mathrm{MHz}, \mathrm{D}_{2} \mathrm{O}\right): \delta=2.50(\mathrm{t}, J=7.1 \mathrm{~Hz}, 2 \mathrm{H}), 2.31-2.24$ (m, $2 \mathrm{H}), 2.11(\mathrm{~s}, 3 \mathrm{H}), 1.56-1.46(\mathrm{~m}, 2 \mathrm{H})$.

${ }^{13} \mathrm{C}$ NMR (101 MHz, $\mathrm{D}_{2} \mathrm{O}$ ): $\delta=55.22,53.31,51.74,44.41,38.96$, 28.54. ${ }^{19}$

\section{$\mathrm{N}$-Methylpiperazine-Functionalized Fiber (P-PANF)}

Commercially available polyacryonitrile fiber with a length of 10 $\mathrm{cm}$ and diameter of $30 \pm 0.5 \mu \mathrm{m}(5.0 \mathrm{~g})$ was refluxed in an aqueous solution of $N$-methyl- $N^{\prime}$-(3-aminopropyl)piperazine (amine: 100 $\mathrm{mL} ; \mathrm{H}_{2} \mathrm{O}: 50 \mathrm{~mL}$ ) for $8 \mathrm{~h}$ to produce the $N$-methylpiperazine functionalized fiber catalyst (P-PANF). Then the fiber was collected by filtration and repeatedly washed with hot water $\left(65-75^{\circ} \mathrm{C}\right)$ until the $\mathrm{pH}$ value of the solution was 7 . It was then dried overnight at $70{ }^{\circ} \mathrm{C}$ under vacuum to give the aminated fiber (P-PANF).

\section{2-Aminothiophenes; General Procedure}

A mixture of activated nitrile $1(5.0 \mathrm{mmol}), 2,5$-dihydroxy-1,4-dithiane $(2 ; 2.5 \mathrm{mmol})$, and $\mathrm{EtOH}(20 \mathrm{~mL})$ was stirred at r.t. for 10 min in a three-necked flask $(100 \mathrm{~mL})$. Then P-PANF $(0.172 \mathrm{~g}$, containing $0.40 \mathrm{mmol}$ tertiary amine groups) was added and the mixture was heated to reflux with stirring for $4 \mathrm{~h}$ [until complete consumption of the starting material as monitored by TLC, eluent: PE-EtOAc, 5:1 (v/v)]. After completion of the reaction, the fiber catalyst was collected by filtration and washed with EtOAc (60 $\mathrm{mL}$ ). The combined filtrates were concentrated and the crude product was purified by column chromatography on silica gel using PEEtOAc $[25: 2(\mathrm{v} / \mathrm{v})]$ as eluent (Table 5).

Ethyl 2-Aminothiophene-3-carboxylate (5a) ${ }^{2 b}$

Yield: $0.792 \mathrm{~g}(89 \%)$; white crystals; $\mathrm{mp} 43-44^{\circ} \mathrm{C}\left(\right.$ Lit. $^{2 \mathrm{~b}} \mathrm{mp} 47-$ $\left.48{ }^{\circ} \mathrm{C}\right)$.

${ }^{1} \mathrm{H}$ NMR $\left(400 \mathrm{MHz}, \mathrm{CDCl}_{3}\right): \delta=6.97(\mathrm{~d}, J=5.8 \mathrm{~Hz}, 1 \mathrm{H}), 6.16(\mathrm{~d}$, $J=5.8 \mathrm{~Hz}, 1 \mathrm{H}), 5.98(\mathrm{~s}, 2 \mathrm{H}), 4.27(\mathrm{q}, J=7.1 \mathrm{~Hz}, 2 \mathrm{H}), 1.33(\mathrm{t}$, $J=7.1 \mathrm{~Hz}, 3 \mathrm{H})$.

${ }^{13} \mathrm{C}$ NMR $\left(101 \mathrm{MHz}, \mathrm{CDCl}_{3}\right): \delta=165.54,162.80,125.96,107.16$, 106.94, 59.80, 14.56 . 
2-Aminothiophene-3-carbonitrile (5b) ${ }^{6}$

Yield: $0.566 \mathrm{~g}(91 \%)$; pale gray crystals; mp $94-95{ }^{\circ} \mathrm{C}$ (Lit. ${ }^{6} \mathrm{mp}$ 97-99 $\left.{ }^{\circ} \mathrm{C}\right)$.

${ }^{1} \mathrm{H}$ NMR $\left(400 \mathrm{MHz}, \mathrm{DMSO}-d_{6}\right): \delta=7.10(\mathrm{~s}, 2 \mathrm{H}), 6.71(\mathrm{~d}, J=5.8$ $\mathrm{Hz}, 1 \mathrm{H}), 6.37(\mathrm{~d}, J=5.8 \mathrm{~Hz}, 1 \mathrm{H})$.

${ }^{13} \mathrm{C}$ NMR $\left(101 \mathrm{MHz}, \mathrm{DMSO}-d_{6}\right): \delta=165.13,125.52,116.49$, $108.62,83.22$.

2-Aminothiophene-3-carboxamide $(5 \mathrm{c})^{2 \mathrm{a}, \mathrm{d}}$

Yield: $0.618 \mathrm{~g}(87 \%)$; white crystals; $\mathrm{mp} 158-160{ }^{\circ} \mathrm{C}$ (Lit. ${ }^{2 \mathrm{a}} \mathrm{mp}$ $\left.160^{\circ} \mathrm{C}\right)$.

${ }^{1} \mathrm{H}$ NMR $\left(400 \mathrm{MHz}, \mathrm{DMSO}-d_{6}\right): \delta=7.22(\mathrm{~s}, 3 \mathrm{H}), 7.04(\mathrm{~d}, J=5.8$ $\mathrm{Hz}, 1 \mathrm{H}), 6.75(\mathrm{~s}, 1 \mathrm{H}), 6.22(\mathrm{~d}, J=5.8 \mathrm{~Hz}, 1 \mathrm{H})$.

${ }^{13} \mathrm{C}$ NMR (101 MHz, DMSO- $\left.d_{6}\right): \delta=167.58,161.71,124.90$, $107.18,105.46$.

2-Amino- $N$-phenylthiophene-3-carboxamide $(5 d)^{3}$

Yield: $0.971 \mathrm{~g}(89 \%)$; pale gray crystals; $\mathrm{mp} 154-155^{\circ} \mathrm{C}\left(\right.$ Lit. $^{3} \mathrm{mp}$ $\left.139^{\circ} \mathrm{C}\right)$.

${ }^{1} \mathrm{H}$ NMR (400 MHz, DMSO- $\left.d_{6}\right): \delta=9.33(\mathrm{~s}, 1 \mathrm{H}), 7.69$ (d, $J=7.8$ $\mathrm{Hz}, 2 \mathrm{H}), 7.41$ (s, $2 \mathrm{H}), 7.37-7.26$ (m, 3 H), 7.07-7.00 (m, $1 \mathrm{H}), 6.33$ $(\mathrm{d}, J=5.9 \mathrm{~Hz}, 1 \mathrm{H})$.

${ }^{13} \mathrm{C}$ NMR (101 MHz, DMSO- $\left.d_{6}\right): \delta=164.11,162.93,139.40$, $128.42,124.32,122.86,120.37,106.95,105.69$.

\section{2-Amino-3-benzoylthiophene $(5 \mathrm{e})^{2 \mathrm{c}}$}

Yield: $0.845 \mathrm{~g}(83 \%)$; bright yellow crystals; $\mathrm{mp} 147-149{ }^{\circ} \mathrm{C}\left(\right.$ Lit. $^{2 \mathrm{c}}$ mp $\left.144-146{ }^{\circ} \mathrm{C}\right)$.

${ }^{1} \mathrm{H}$ NMR (400 MHz, $\left.\mathrm{CDCl}_{3}\right): \delta=7.70-7.65(\mathrm{~m}, 2 \mathrm{H}), 7.51-7.41(\mathrm{~m}$, $3 \mathrm{H}), 7.01(\mathrm{~s}, 2 \mathrm{H}), 6.87(\mathrm{~d}, J=5.9 \mathrm{~Hz}, 1 \mathrm{H}), 6.11(\mathrm{~d}, J=5.9 \mathrm{~Hz}, 1$ $\mathrm{H})$.

${ }^{13} \mathrm{C}$ NMR $\left(101 \mathrm{MHz}, \mathrm{CDCl}_{3}\right): \delta=191.37,166.34,140.96,130.85$, $128.27,127.89,115.26,106.20$.

2-Amino-3-(2-methylbenzoyl)thiophene (5f) ${ }^{20}$

Yield: $0.880 \mathrm{~g}(81 \%)$; yellow crystals; $\mathrm{mp} 151-153{ }^{\circ} \mathrm{C}$ (Lit. ${ }^{20} \mathrm{mp}$ $\left.158-159^{\circ} \mathrm{C}\right)$.

IR (KBr): 3344, 3227, 3113, 1589, $1443 \mathrm{~cm}^{-1}$.

${ }^{1} \mathrm{H}$ NMR (400 MHz, DMSO- $\left.d_{6}\right): \delta=8.36(\mathrm{~s}, 2 \mathrm{H}), 7.37-7.17(\mathrm{~m}, 4$ H), $6.29(\mathrm{~d}, J=5.9 \mathrm{~Hz}, 1 \mathrm{H}), 6.18(\mathrm{~d}, J=5.9 \mathrm{~Hz}, 1 \mathrm{H}), 2.22(\mathrm{~s}, 3 \mathrm{H})$.

${ }^{13} \mathrm{C}$ NMR (101 MHz, DMSO- $\left.d_{6}\right): \delta=191.08,166.75,141.18$, 133.97, 130.36, 128.81, 126.46, 126.37, 125.29, 114.09, 106.17, 18.97.

HRMS (ESI): $m / z$ calcd for $\mathrm{C}_{12} \mathrm{H}_{12} \mathrm{NOS}[\mathrm{M}+\mathrm{H}]^{+}: 218.0634$; found: 218.0636 .

2-Amino-3-(4-methylbenzoyl)thiophene (5g)

Yield: $0.892 \mathrm{~g}(82 \%)$; yellow crystals; $\mathrm{mp} 146-148{ }^{\circ} \mathrm{C}$.

IR (KBr): 3375, 3254, 3138, 1588, $1442 \mathrm{~cm}^{-1}$.

${ }^{1} \mathrm{H}$ NMR (400 MHz, DMSO- $\left.d_{6}\right): \delta=8.30(\mathrm{~s}, 2 \mathrm{H}), 7.50(\mathrm{~d}, J=8.0$ $\mathrm{Hz}, 2 \mathrm{H}), 7.27$ (d, $J=8.0 \mathrm{~Hz}, 2 \mathrm{H}), 6.76(\mathrm{~d}, J=5.9 \mathrm{~Hz}, 1 \mathrm{H}), 6.25$ $(\mathrm{d}, J=5.9 \mathrm{~Hz}, 1 \mathrm{H}), 2.36(\mathrm{~s}, 3 \mathrm{H})$.

${ }^{13} \mathrm{C}$ NMR (101 MHz, DMSO- $\left.d_{6}\right): \delta=188.99,167.10,140.34$, 138.14, 128.68, 127.83, 126.61, 112.96, 106.01, 20.96.

HRMS (ESI): $m / z$ calcd for $\mathrm{C}_{12} \mathrm{H}_{12} \mathrm{NOS}[\mathrm{M}+\mathrm{H}]^{+}: 218.0634$; found: 218.0634 .

2-Amino-3-(4-methoxybenzoyl)thiophene (5h)

Yield: $0.933 \mathrm{~g}(80 \%)$; yellow crystals; $\mathrm{mp} 141-143{ }^{\circ} \mathrm{C}$.

IR (KBr): 3368, 3239, 3127, 1595, $1445 \mathrm{~cm}^{-1}$.

${ }^{1} \mathrm{H}$ NMR $\left(400 \mathrm{MHz}, \mathrm{CDCl}_{3}\right): \delta=7.69(\mathrm{~d}, J=8.6 \mathrm{~Hz}, 2 \mathrm{H}), 6.98$ $6.89(\mathrm{~m}, 5 \mathrm{H}), 6.13(\mathrm{~d}, J=5.8 \mathrm{~Hz}, 1 \mathrm{H}), 3.86(\mathrm{~s}, 3 \mathrm{H})$.
${ }^{13} \mathrm{C} \mathrm{NMR}\left(101 \mathrm{MHz}, \mathrm{CDCl}_{3}\right): \delta=190.38,165.85,161.95,133.51$, $130.52,127.90,115.33,113.53,106.10,55.50$.

HRMS (ESI): $m / z$ calcd for $\mathrm{C}_{12} \mathrm{H}_{12} \mathrm{NO}_{2} \mathrm{~S}[\mathrm{M}+\mathrm{H}]^{+}:$234.0583; found: 234.0585 .

\section{2-Amino-3-(4-chlorobenzoyl)thiophene (5i) ${ }^{2 c}$}

Yield: $1.010 \mathrm{~g}(85 \%)$; bright yellow crystals; $\mathrm{mp} 168-170{ }^{\circ} \mathrm{C}\left(\right.$ Lit. $^{2 \mathrm{c}}$ mp $\left.168-170{ }^{\circ} \mathrm{C}\right)$.

${ }^{1} \mathrm{H}$ NMR $\left(400 \mathrm{MHz}\right.$, DMSO- $\left.d_{6}\right): \delta=8.39(\mathrm{~s}, 2 \mathrm{H}), 7.61(\mathrm{~d}, J=8.5$ $\mathrm{Hz}, 2 \mathrm{H}), 7.53(\mathrm{~d}, J=8.5 \mathrm{~Hz}, 2 \mathrm{H}), 6.73(\mathrm{~d}, J=5.9 \mathrm{~Hz}, 1 \mathrm{H}), 6.28$ $(\mathrm{d}, J=5.9 \mathrm{~Hz}, 1 \mathrm{H})$.

${ }^{13} \mathrm{C}$ NMR (101 MHz, DMSO- $\left.d_{6}\right): \delta=187.64,167.67,139.50$, $135.15,129.60,128.30,126.28,112.68,106.43$.

\section{2-Amino-3-(2,2-dimethylpropanoyl)thiophene (5j) ${ }^{\mathbf{3}}$}

Yield: $0.760 \mathrm{~g}(83 \%)$; light yellow crystals; $\mathrm{mp} 99-100{ }^{\circ} \mathrm{C}$ (Lit. ${ }^{3} \mathrm{mp}$ $\left.101{ }^{\circ} \mathrm{C}\right)$.

${ }^{1} \mathrm{H}$ NMR $\left(400 \mathrm{MHz}, \mathrm{CDCl}_{3}\right): \delta=7.19(\mathrm{~d}, J=6.0 \mathrm{~Hz}, 1 \mathrm{H}), 6.92(\mathrm{~s}$, $2 \mathrm{H}), 6.13(\mathrm{~d}, J=6.0 \mathrm{~Hz}, 1 \mathrm{H}), 1.33(\mathrm{~s}, 9 \mathrm{H})$.

${ }^{13} \mathrm{C} \mathrm{NMR}\left(101 \mathrm{MHz}, \mathrm{CDCl}_{3}\right): \delta=202.30,166.52,126.38,112.98$, $105.48,43.81,28.00$.

\section{2-Amino-3-(2-thiophenoyl)thiophene (5k)}

Yield: $0.856 \mathrm{~g}(82 \%)$; bright yellow crystals; mp $122-124{ }^{\circ} \mathrm{C}$.

IR (KBr): 3362, 3258, 3136, 1584, $1437 \mathrm{~cm}^{-1}$.

${ }^{1} \mathrm{H}$ NMR (400 MHz, DMSO- $\left.d_{6}\right): \delta=8.31(\mathrm{~s}, 2 \mathrm{H}), 7.88-7.83(\mathrm{~m}, 1$ H), 7.75-7.71 (m, 1 H), 7.26-7.16 (m, 2 H), 6.35 (d, $J=5.9 \mathrm{~Hz}, 1$ $\mathrm{H})$.

${ }^{13} \mathrm{C}$ NMR (101 MHz, DMSO- $\left.d_{6}\right): \delta=179.41,167.64,145.19$, $131.68,130.44,128.02,125.45,112.13,106.87$.

HRMS (ESI): $m / z$ calcd for $\mathrm{C}_{9} \mathrm{H}_{8} \mathrm{NOS}_{2}[\mathrm{M}+\mathrm{H}]^{+}: 210.0042$; found: 210.0041 .

\section{2-Amino-3-(2-furoyl)thiophene (5I)}

Yield: $0.802 \mathrm{~g}(83 \%)$; yellow crystals; $\mathrm{mp} 113-114{ }^{\circ} \mathrm{C}$.

IR (KBr): 3337, 3236, 3131, 1587, 1468, $1436 \mathrm{~cm}^{-1}$.

${ }^{1} \mathrm{H}$ NMR $\left(400 \mathrm{MHz}, \mathrm{DMSO}-d_{6}\right): \delta=8.43(\mathrm{~s}, 2 \mathrm{H}), 7.93(\mathrm{~s}, 1 \mathrm{H})$, $7.45(\mathrm{~d}, J=6.0 \mathrm{~Hz}, 1 \mathrm{H}), 7.23(\mathrm{~d}, J=3.3 \mathrm{~Hz}, 1 \mathrm{H}), 6.71-6.65(\mathrm{~m}, 1$ $\mathrm{H}), 6.34(\mathrm{~d}, J=6.0 \mathrm{~Hz}, 1 \mathrm{H})$.

${ }^{13} \mathrm{C}$ NMR (101 MHz, DMSO- $\left.d_{6}\right): \delta=174.53,168.28,153.21$, 145.82, 125.28, 116.19, 112.03, 111.59, 106.74.

HRMS (ESI): $m / z$ calcd for $\mathrm{C}_{9} \mathrm{H}_{8} \mathrm{NO}_{2} \mathrm{~S}[\mathrm{M}+\mathrm{H}]^{+}: 194.0270$; found: 194.0273.

\section{2-Amino-3-(2-naphthoyl)thiophene (5m) ${ }^{2 \mathrm{f}}$}

Yield: $1.001 \mathrm{~g}(79 \%)$; bright yellow crystals; $\mathrm{mp} 152-156^{\circ} \mathrm{C}\left(\right.$ Lit. $^{2 \mathrm{f}}$ mp $\left.143-145^{\circ} \mathrm{C}\right)$.

IR (KBr): 3351, 3245, 3139, 1592, $1441 \mathrm{~cm}^{-1}$.

${ }^{1} \mathrm{H}$ NMR $\left(400 \mathrm{MHz}, \mathrm{DMSO}-d_{6}\right): \delta=8.40(\mathrm{~s}, 2 \mathrm{H}), 8.18(\mathrm{~s}, 1 \mathrm{H})$, 8.09-7.95 (m, 3 H), 7.72-7.68 (m, 1 H), 7.63-7.55 (m, $2 \mathrm{H}), 6.84$ $(\mathrm{d}, J=5.9 \mathrm{~Hz}, 1 \mathrm{H}), 6.30(\mathrm{~d}, J=5.9 \mathrm{~Hz}, 1 \mathrm{H})$.

${ }^{13} \mathrm{C}$ NMR (101 MHz, DMSO- $\left.d_{6}\right): \delta=189.00,167.39,138.15$, $133.70,132.03,128.88,127.83,127.68,127.56,127.39,126.70$, 126.62, 124.92, 113.11, 106.26.

HRMS (ESI): $m / z$ calcd for $\mathrm{C}_{15} \mathrm{H}_{12} \mathrm{NOS}[\mathrm{M}+\mathrm{H}]^{+}: 254.0634$; found: 254.0634 .

\section{2-Amino-3-tosylthiophene (5n) $)^{2 \mathrm{~g}}$}

Yield: $0.823 \mathrm{~g}(65 \%)$; tan crystals; $\mathrm{mp} 130-131^{\circ} \mathrm{C}$, (Lit. ${ }^{2 \mathrm{~g}} \mathrm{mp} 131-$ $\left.132{ }^{\circ} \mathrm{C}\right)$.

${ }^{1} \mathrm{H}$ NMR (400 MHz, DMSO- $d_{6}$ ): $\delta=7.79(\mathrm{~d}, J=8.0 \mathrm{~Hz}, 2 \mathrm{H}), 7.38$ $(\mathrm{d}, J=8.0 \mathrm{~Hz}, 2 \mathrm{H}), 6.98(\mathrm{~s}, 2 \mathrm{H}), 6.73(\mathrm{~d}, J=5.9 \mathrm{~Hz}, 1 \mathrm{H}), 6.38(\mathrm{~d}$, $J=5.9 \mathrm{~Hz}, 1 \mathrm{H}), 2.36(\mathrm{~s}, 3 \mathrm{H})$. 
${ }^{13} \mathrm{C}$ NMR $\left(101 \mathrm{MHz}, \mathrm{DMSO}-d_{6}\right): \delta=159.74,143.18,140.46$ $129.73,125.85,124.19,110.61,108.07,20.92$.

\section{Acknowledgment}

The authors are grateful for the financial support from the Key Program of the National Natural Science Foundation of China (No: 20834002).

Supporting Information for this article is available online at http://www.thieme-connect.com/ejournals/toc/synthesis.

\section{References}

(1) For reviews, see: (a) Gewald, K. Chem. Heterocycl. Compd. 1976, 12, 1077. (b) Puterová, Z.; Krutošíková, A.; Végh, D. ARKIVOC 2010, (i), 209. (c) Wang, K.; Kim, D.; Dömling, A. J. Comb. Chem. 2010, 12, 111. (d) Huang, Y.; Dömling, A. Mol. Divers. 2011, 15, 3. (e) Sabnis, R. W.; Rangnekar, D. W.; Sonawane, N. D. J. Heterocycl. Chem. 1999, 36, 333.

(2) (a) Dumaître, B.; Dodic, N. J. Med. Chem. 1996, 39, 1635. (b) Gütschow, M.; Kuerschner, L.; Neumann, U.; Pietsch, M.; Löser, R.; Koglin, N.; Eger, K. J. Med. Chem. 1999, 42, 5437. (c) Aurelio, L.; Valant, C.; Flynn, B. L.; Sexton, P. M.; White, J. M.; Christopoulos, A.; Scammells, P. J. J. Med. Chem. 2010, 53, 6550. (d) Theoclitou, M. E.; Aquila, B.; Block, M. H.; Brassil, P. J.; Castriotta, L.; Code, E.; Collins, M. P.; Davies, A. M.; Deegan, T.; Ezhuthachan, J.; Filla, S.; Freed, E.; Hu, H.; Huszar, D.; Jayaraman, M.; Lawson, D.; Lewis, P. M.; Nadella, M. V. P.; Oza, V.; Padmanilayam, M.; Pontz, T.; Ronco, L.; Russell, D.; Whitston, D.; Zheng, X. J. Med. Chem. 2011, 54, 6734. (e) Baraldi, P. G.; Romagnoli, R.; Pavani, M. G.; Nuñez, M. C.; Tabrizi, M. A.; Shryock, J. C.; Leung, E.; Moorman, A. R.; Uluoglu, C.; Iannotta, V.; Merighi, S.; Borea, P. A. J. Med. Chem. 2003, 46, 794. (f) Tranberg, C. E.; Zickgraf, A.; Giunta, B. N.; Luetjens, H.; Figler, H.; Murphree, L. J.; Falke, R.; Fleischer, H.; Linden, J.; Scammells, P. J.; Olsson, R. A. J. Med. Chem. 2002, 45, 382. (g) Stephens, C. E.; Felder, T. M.; Sowell, J. W.; Andrei, G.; Balzarini, J.; Snoeck, R.; Clercq, E. D. Bioorg. Med. Chem. 2001, 9, 1123. (h) Zeika, O.; Hartmann, H. Synthesis 2004, 377. (i) Zhang, H. Q.; Yang, G. C.; Chen, J. N.; Chen, Z. X. Synthesis 2004, 3055.

(3) Hesse, S.; Perspicace, E.; Kirsch, G. Tetrahedron Lett. 2007, 48,5261 .
(4) Lütjens, H.; Zickgraf, A.; Figler, H.; Linden, J.; Olsson, R. A.; Scammells, P. J. J. Med. Chem. 2003, 46, 1870.

(5) (a) Hallas, G.; Towns, A. D. Dyes Pigm. 1997, 33, 319 (b) Yen, M. S.; Wang, I. J. Dyes Pigm. 2005, 67, 183.

(6) Dufresne, S.; Bourgeaux, M.; Skene, W. G. J. Mater. Chem. 2007, 17, 1166.

(7) (a) Barnes, D. M.; Haight, A. R.; Hameury, T.; McLaughlin, M. A.; Mei, J.; Tedrow, J. S.; Toma, J. D. R. Tetrahedron 2006, 62, 11311. (b) Moeinpour, F.; Omidinia, R.; Dorostkar-Ahmadi, N.; Khoshdeli, B. Bull. Korean Chem. Soc. 2011, 32, 2091.

(8) Sridhar, M.; Rao, R. M.; Baba, N. H. K.; Kumbhare, R. M. Tetrahedron Lett. 2007, 48, 3171.

(9) Tormyshev, V. M.; Trukhin, D. V.; Rogozhnikova, O. Y.; Mikhalina, T. V.; Troitskaya, T. I.; Flinn, A. Synlett 2006, 2559.

(10) Wang, T.; Huang, X. G.; Liu, J.; Li, B.; Wu, J. J.; Chen, K. X.; Zhu, W. L.; Xu, X. Y.; Zeng, B. B. Synlett 2010, 1351.

(11) (a) Hu, Y.; Chen, Z. C.; Le, Z. G.; Zheng, Q. G. Synth. Commun. 2004, 34, 3801. (b) Hu, Y.; Wei, P.; Huang, H.; Han, S. Q.; Ouyang, P. K. Heterocycles 2006, 68, 375.

(12) Hoener, A. P. F.; Henkel, B.; Gauvina, J. C. Synlett 2003, 63.

(13) Mojtahedi, M. M.; Abaee, M. S.; Mahmoodi, P.; Adib, M. Synth. Commun. 2010, 40, 2067.

(14) (a) Vatutsina, O. M.; Soldatov, V. S.; Sokolova, V. I.; Johann, J.; Bissen, M.; Weissenbacher, A. React. Funct. Polym. 2007, 67, 184. (b) Liu, R. X.; Zhang, B. W.; Tang, H. X. React. Funct. Polym. 1999, 39, 71. (c) Moroi, G.; Bilba, D.; Bilba, N. Polym. Degrad. Stab. 2004, 84, 207.

(15) (a) Zhang, L. H.; Zhang, X. S.; Li, P. P.; Zhang, W. Q. React. Funct. Polym. 2009, 69, 48. (b) Zhang, L. H.; Li, Z. W.; Chang, R. X.; Chen, Y.; Zhang, W. Q. React. Funct. Polym. 2009, 69, 234

(16) Shunkevich, A. A.; Akulich, Z. I.; Mediak, G. V.; Soldatov, V. S. React. Funct. Polym. 2005, 63, 27.

(17) Li, G. W.; Xiao, J.; Zhang, W. Q. Green Chem. 2011, 13, 1828 .

(18) (a) Rice, L. M.; Gorgan, C. H. J. Org. Chem. 1955, 20, 1687. (b) Hamilton, C. J.; Saravanamuthu, A.; Fairlamb, A. H.; Eggleston, I. M. Bioorg. Med. Chem. 2003, 11, 3683.

(19) (a) Hosino, K. Bull. Chem. Soc. Jpn. 1943, 18, 97. (b) Ovat, A.; Li, Z. Z.; Hampton, C. Y.; Asress, S. A.; Fernández, F. M.; Glass, J. D.; Powers, J. C. J. Med. Chem. 2010, 53, 6326.

(20) Hirohashi, T.; Inaba, S.; Yamamoto, H. Bull. Chem. Soc. Jpn. 1975, 48, 147. 